\title{
Cynthia Skenazi, Une écriture de la vieillesse: les «Excremens d'un vieil esprit» et la vaniti montaignienne
}

\section{Filippo Fassina}

\section{(2) OpenEdition}

1 Journals

\section{Edizione digitale}

URL: http://journals.openedition.org/studifrancesi/9847

DOI: 10.4000/studifrancesi.9847

ISSN: 2421-5856

\section{Editore}

Rosenberg \& Sellier

\section{Edizione cartacea}

Data di pubblicazione: 1 octobre 2007

Paginazione: 431

ISSN: 0039-2944

\section{Notizia bibliografica digitale}

Filippo Fassina, «Cynthia Skenazi, Une écriture de la vieillesse: les «Excremens d"un vieil esprit» et la vaniti montaignienne», Studi Francesi [Online], 152 (LI | II) | 2007, online dal 28 septembre 2017, consultato il 08 janvier 2021. URL: http://journals.openedition.org/studifrancesi/9847 ; DOI: https://doi.org/ 10.4000/studifrancesi.9847

Questo documento è stato generato automaticamente il 8 janvier 2021.

\section{(c) 9 (i) $\Theta$}

Studi Francesi è distribuita con Licenza Creative Commons Attribuzione - Non commerciale - Non opere derivate 4.0 Internazionale. 


\title{
Cynthia Skenazi, Une écriture de la vieillesse: les «Excremens d'un vieil esprit» et la vaniti montaignienne
}

\author{
Filippo Fassina
}

\section{NOTIZIA}

CYNTHIA SKENAZI, Une écriture de la vieillesse: les «Excremens d'un vieil esprit» et la vaniti montaignienne, «Bibliothèque d'Humanisme et Renaissance», LXVIII, 2 (2006), pp. 289-305.

L'A. concentra la propria attenzione sulla tematica dell'invecchiamento e della salute psico-fisica nell'opera di Montaigne, soffermandosi soprattutto sulle implicazioni letterarie. Il parallelo fortemente scatologico tra la produzione letteraria e gli escrementi è, in primo luogo, visto come una prudente dichiarazione di modestia, ma il topos del decadimento fisico è anche il punto di partenza per una riflessione sulla vanità, a cui è dedicato un intero capitolo degli Essais (III, 9). Lo spunto biblico della vanitas porta, secondo la studiosa, all'immagine tradizionale della vita intesa come viaggio esistenziale e questo vagabondaggio si riflette anche sullo stile che risulta prolisso e a tratti disordinato. La vecchiaia, dal punto letterario, risente di due immagini tradizionali: da un lato la satira degli âgés e della loro volubilità, di matrice erasmiana, dall'altro quello della perdita della memoria e del ricordo che, secondo Montaigne e in opposizione al De senectute di Cicerone, influenza positivamente la produzione letteraria. Inoltre, all'invecchiamento è anche strettamente legato il problema della trasmissione dei beni e dell'amministrazione domestica. L'A. sottolinea dunque come il passare del tempo influenzi tutti gli aspetti dell'esistenza di Montaigne, trattandosi però sempre di un'esperienza soggettiva e personale che va ben al di là della tradizione e del milieu culturale. Per Montaigne lo scopo dell'esistenza è «jouir de son estre» e ciò che resta della vecchiaia non è che «excremens d'un vieil esprit», ma è l'arte a dare un senso a tutto questo, proprio come accade per le rovine di Roma, altra 
grande tematica degli Essais, collegata, secondo la Skenazi, con il viaggio in Italia di Montaigne. L'A. pone l'accento infine sul fatto che all'epoca di Montaigne rovine e vecchiaia si fondono nel tema delle vanités e la sua originalità sta proprio nel coniugare questi motivi, rendendo la vecchiaia un alimento per la letteratura piuttosto che un ostacolo. 